\title{
TRAÇOS DE CIENTIFICIDADE, DIDATICIDADE E LAICIDADE EM ARTIGOS DA REVISTA 'CIÊNCIA HOJE' RELACIONADOS À QUÍMICA*
}

\section{Scientificity, didacticity, and laicity traces in articles pub- lished in Ciência Hoje magazine related to Chemistry}

\author{
Salete Linhares Queiroz ${ }^{1}$. Luciana Nobre de Abreu Ferreira ${ }^{2}$
}

\begin{abstract}
Resumo: Neste trabalho temos como objetivo a análise de artigos publicados na revista Ciência Hoje, visando auxiliar o professor no seu uso como recurso didático em aulas de química. Os artigos foram analisados com base na Análise de Discurso de linha francesa, considerando os estudos de Zamboni a respeito das características do discurso da divulgação científica, especialmente a identificação dos traços de cientificidade, didaticidade e laicidade. A identificação de tais traços se traduz em um artifício relevante para o professor de química, que poderá escolher textos mais adequados aos objetivos educacionais.
\end{abstract}

Palavras-chave: Divulgação científica. Ensino de química. Revista Ciência Hoje. Análise do discurso.

\begin{abstract}
The objective of this study is to investigate articles published in Ciência Hoje magazine and to assist teachers to use them in chemistry classes. The articles were analyzed from the perspective of French Discourse Analysis, considering Zamboni studies, according to the concept of popularization of scientific discourse specifically the identification of scientificity, didacticity, and laicity traces. Such identification is an important tool for the chemistry teacher to choose the most suitable articles for educational purposes.
\end{abstract}

Keywords: Popularization of science. Chemistry teaching. Ciência Hoje magazine. Discourse analysis.

\footnotetext{
* As autoras agradecem à FAPESP (Processo 2008/10577-5) e ao CNPq (Processo 302455/2009-4) pelo auxílio financeiro.

${ }^{1}$ Universidade de São Paulo (USP), Instituto de Química de São Carlos, Departamento de Físico-Química, Avenida Trabalhador São-carlenese, n. 400, caixa postal 780, Centro, CEP 13560-970, São Carlos, SP, Brasil. Email:salete@iqsc.usp.br

${ }^{2}$ Universidade Federal do Piauí (UFPI), Centro de Ciências da Natureza, Teresina, PI, Brasil.
} 
Queiroz, S. L.; Ferreira, L. N. A.

\section{Introdução}

As atividades de divulgação científica têm evoluído ao longo do tempo, acompanhando o próprio desenvolvimento da ciência, e podem estar orientadas para diferentes objetivos, dentre os quais destacamos os objetivos educacionais. Nesse sentido, textos de divulgação científica (TDC) das mais diversas ordens (artigos de revista, livros etc.) têm sido apontados como um bom artifício no auxílio ao ensino formal, sobretudo quando se deseja estender o ensino de conteúdos à preparação dos estudantes para a cidadania.

Dentre os benefícios apontados por vários pesquisadores advindos do uso de TDC em ambientes de ensino estão: localização do conteúdo tratado nos livros didáticos em contexto mais abrangente e articulação com o cotidiano dos alunos; desenvolvimento de hábitos de leitura e formação de leitores críticos; inserção de novas abordagens e temáticas nas aulas de ciências; promoção de maior envolvimento e participação dos alunos nas atividades em classe; favorecimento da compreensão sobre o processo de construção da ciência (MARTINS; NASCIMENTO; ABREU, 2004; SILVA; ALMEIDA, 2005; TERRAZZAN; GABANA, 2003).

Os TDC publicados na revista Ciência Hoje - do Instituto Ciência Hoje, organização social de interesse público vinculada à Sociedade Brasileira para o Progresso da Ciência (SBPC) - são dignos de nota. Essa revista oferece um panorama da produção intelectual e tecnológica das universidades, institutos e centros de pesquisa nacionais e internacionais, e se dirige à comunidade acadêmica, aos professores e estudantes de Ensino Médio e à sociedade em geral (IVANISSEVICH, 2002).

Vale salientar que a revista Ciência Hoje goza de excelente reputação no meio acadêmico e constitui um veículo de matérias da atualidade e de interesse social. Além disso, possui fácil acesso pelos professores, pois costuma estar presente em bibliotecas públicas e escolas do nível Básico. Assim, acreditando que as reportagens publicadas na revista podem ser parte integrante de um leque de recursos disponíveis para uso didático em aulas de química, temos como objetivo, neste manuscrito, apresentar a análise de TDC relacionados à química, tendo em vista a identificação de traços de cientificidade, didaticidade e laicidade presentes na superfície desses textos. Para tanto, buscamos subsídios na Análise do Discurso de linha francesa, em particular as considerações de Zamboni (2001) a respeito das características do discurso da divulgação científica.

Esperamos que a discussão de tais traços suavize a tarefa do professor na escolha de TDC para uso em aulas de química, uma vez que a identificação da predominância de um ou de outro traço nos textos pode ser adotada como um dos critérios para a programação e a posterior condução das atividades didáticas. Nesse contexto, compartilhamos com Terrazzan e Gabana (2003) o entendimento de que existe a necessidade de realização, por parte do professor, de uma leitura cuidadosa dos TDC, antes do seu uso em ambientes de ensino, com destaque para conceitos e trechos de maior relevância, assim como a preparação de intervenções para explicações e comentários sobre os trechos selecionados. Os resultados apresentados neste trabalho poderão servir de subsídio para essa preparação prévia. 
Traços de cientificidade, didaticidade e laicidade ...

\section{Referencial teórico para a análise dos TDC}

Lançamos mão do referencial teórico da Análise de Discurso francesa para a análise dos TDC, especialmente as considerações de Zamboni (2001) a respeito de características do discurso da divulgação científica. A autora tomou como fundamentos teóricos principais a noção de sujeito e a concepção de estilo, com as quais operou a análise descrita em seu trabalho. Rejeitando a noção de sujeito completamente assujeitado (sujeito apenas como um ponto pelo qual passariam discursos prévios) e adotando a concepção de sujeito ativo, que age no interior de sistemas em processo, ela afirma que é preciso incorporar as imagens que o locutor projeta nos recursos expressivos que a língua põe à sua disposição, não só para gerar um efeito de sentido, mas também para gerar um valor social, consideradas as condições de produção do discurso.

Dessa forma, não havendo um interlocutor real, será ele pressuposto pelo enunciador, a partir da caracterização do grupo social ao qual pertence o locutor, sendo, portanto, a presença real de um ou mais indivíduos ou a imagem idealizada de uma audiência imaginária. Segundo Bakhtin (1992 apud ZAMBONI, 2001, p. 11):

O falante tende a orientar o seu discurso, com o seu círculo determinante, para o círculo alheio de quem compreende, entrando em relação dialógica com os aspectos deste âmbito. O locutor penetra no horizonte alheio de seu ouvinte, constrói sua enunciação no território de outrem, sobre o fundo aperceptivo do seu ouvinte.

A teoria do estilo trata do modo como estão relacionados ativamente a forma e o conteúdo. De acordo com a autora, o estilo reflete a escolha, e, aos recursos estilísticos, estão agregados os diferentes valores de uso. Essa concepção está assumida e incorporada no processo de interpretação do TDC por conta do tratamento que se dá à linguagem no processamento da divulgação, resultante de um verdadeiro trabalho de 'escolha' das formas acionadas, com o intuito de tornar compreensível, para um público leigo, uma linguagem que lhe é, a princípio, inacessível. Dessa forma, a teoria do estilo concede espaço para abrigar a concepção de valor social, uma vez que, na produção de divulgação científica, ocorre a escolha, por parte do locutor, "de recursos expressivos aos quais se agregou um valor social de 'mais fácil', 'mais compreensível', 'de maior assimilação'[...]” (ZAMBONI, 2001, p. 20).

Assim, o processo de enunciação engloba fatores condicionantes da produção discursiva, como "o veículo ou o suporte do texto-produto, o propósito comunicacional, o assunto em pauta, o tipo de texto, além de outros" (ZAMBONI, 2001, p. 12).

Segundo Zamboni (2001), ao ser direcionado a um público não científico, o discurso da divulgação científica está sujeito a determinadas condições de produção que têm fortes condicionantes na determinação das posições do enunciador e destinatário, no tratamento a ser dado no assunto e na construção composicional. Com isto, o que se pode notar nas ocorrências desse tipo de discurso é a "superposição de traços de cientificidade, laicidade e didaticidade, que se deixam mostrar, em graus variados, na superfície dos textos" (ZAMBONI, 2011, p. 96). 
Queiroz, S. L.; Ferreira, L. N. A.

Assim, consideramos, em nossa análise, que os traços de cientificidade são aqueles típicos do discurso científico. No entanto, nos TDC, esses traços revelam não apenas aspectos explícitos da práxis científica, mas, também, implícitos (como características pessoais de cientistas, consequências negativas de certos produtos de ciência, entre outros). Ou seja, são marcas de estratégias enunciativas pressupondo um leitor que busca compreender as pesquisas científicas que envolvem a temática do TDC, entender como a ciência é praticada, suas finalidades, a demanda de pesquisas científicas, entre outros.

Os traços de laicidade compreendem elementos inerentes ao discurso cotidiano, os quais abarcam as várias formas de contextualização. Traços dessa natureza são evidenciados por meio de recursos discursivos que envolvem a relação da temática científica tratada no TDC com o cotidiano do leitor, portanto, incluem procedimentos de aproximação, simplificação, exemplificação, fórmulas de envolvimento, entre outros. Os traços de didaticidade são próprios do discurso didático, os quais incluem procedimentos como explicações, recapitulações e orientações metodológicas. Neste caso, o enunciador pressupõe um leitor que necessita adquirir certo saber para dar cabo da leitura. Logo, aciona uma série de estratégias com o objetivo de favorecer o entendimento de seu destinatário sobre os aspectos científicos tratados no TDC.

Cabe destacar que os aspectos que caracterizam a cientificidade, didaticidade e laicidade dos textos são abrangentes e não se encerram na identificação descrita no presente manuscrito. Ademais, a caracterização dos traços de cientificidade, didaticidade e laicidade fica mais evidente quando apresentada e exemplificada ao longo da análise dos textos.

Dessa forma, com a finalidade de destacar esses traços nos textos, Zamboni (2001) descreveu três noções para melhor caracterizá-los: situacional, formal e funcional. A caracterização situacional está voltada para os personagens da cena enunciativa. Como exemplo, a autora coloca que, no "discurso didático", um dos interlocutores assume a posição daquele que detém um saber que supostamente seu interlocutor não tem. Cabe-lhe, assim, partilhar, passar para o outro, parte desse saber. Portanto, podem ser determinados graus de didaticidade pela distância pressuposta entre os conhecimentos do enunciador (aquele que sabe) e do destinatário (aquele que não sabe). A caracterização de natureza formal investiga, nos textos, "formas relacionadas aos procedimentos de denominação, exemplificação, explicação, classificação" (ZAMBONI, 2001, p. 96). De acordo com a autora, as paráfrases, por exemplo, seriam traços formais de didaticidade. Esses traços formais permitiriam descobrir as representações que os enunciadores fazem das lacunas de seus destinatários e atribuir, por consequência, graus diferentes de didaticidade, laicidade e cientificidade.

A caracterização do tipo funcional permitiria descobrir diferenças nos modos de transmissão dos conhecimentos científicos, numa abordagem pragmática, tendo, também, marcas formais como base para a identificação: "seria o caso de distinguir nuances performativas particulares associadas a diferentes objetivos de didaticidade ('eu digo isso a você para que o saiba'), de competencialização ('eu digo isso para tornar você mais competente'), de imposição ('fazer agir'), de exposição ('fazer conhecer os resultados de uma pesquisa')" (ZAMBONI, 2001, p. 97).

Diante de tais considerações, percebe-se que o sujeito enunciador não se constrói isoladamente, tampouco a atividade discursiva. Essas operações são interdependentes, uma vez que o enunciador se constrói orientado para um destinatário específico, numa dada situação 
Traços de cientificidade, didaticidade e laicidade ...

enunciativa. Daí a importância da linguagem na definição do quadro analítico no qual serão avaliados os TDC, pois é nela que se constituem o enunciador, o destinatário e o referente.

\section{Percurso metodológico}

Como ponto de partida, fizemos a leitura de todos os números publicados da revista Ciência Hoje entre os anos de 2004 e 2008. Embora tenhamos localizado reportagens relacionadas direta ou indiretamente à química, em seções como $O$ leitor pergunta, Mundo de ciência, $A$ propósito, Em dia, Primeira linha, Ensaio, Memória, optamos por analisar apenas os artigos completos da revista. Estes oferecem matérias mais ricas em detalhes, proporcionando uma maior variedade de possibilidades de uso didático. De acordo com as normas da própria revista, os artigos devem apresentar uma abordagem ampla e aprofundada sobre temas de grande abrangência e interesse geral, enquanto as seções focalizam assuntos específicos.

Considerando o referido recorte, identificamos um total de 29 artigos. Após leitura criteriosa e análise de todos eles, elegemos sete para a discussão neste trabalho, cujos títulos, mês/ano de publicação e área a que se relacionam (indicada na retranca dos artigos) são apresentados no Quadro 1. Acreditamos que esta escolha representa a ocorrência dos elementos característicos de cientificidade, didaticidade e laicidade no total de TDC analisados, de modo que nos permita evidenciar a forma como essas marcas discursivas estão presentes na superfície desses textos. Portanto, a princípio, os outros textos analisados poderiam ter servido igualmente aos propósitos visados.

Quadro 1. Artigos relacionados à química, analisados neste trabalho na perspectiva de identificação de traços de cientificidade, didaticidade e laicidade.

\begin{tabular}{|c|l|l|c|}
\hline & \multicolumn{1}{|c|}{ Título do artigo } & \multicolumn{1}{|c|}{ Área } & Mês/Ano \\
\hline 1 & Eletricidade estática: onde ficam as cargas? & Química & Set/04 \\
\hline 2 & Catalisadores: em busca de estruturas de superfície & Química & Dez/04 \\
\hline 3 & $\begin{array}{l}\text { Nanociência e nanotecnologia: o gigantesco e promissor mundo do } \\
\text { muito pequeno }\end{array}$ & $\begin{array}{l}\text { Nanociência e } \\
\text { Nanotecnologia }\end{array}$ & Jul/05 \\
\hline 4 & Energia verde & Tecnologia Energética & Nov/06 \\
\hline 5 & A química do cosmo & Cosmoquímica & Mai/07 \\
\hline 6 & Aquímica na padaria: o açúcar nos pães dietéticos & Química & Abr/08 \\
\hline 7 & $\begin{array}{l}\text { Solução biode(sa)gradável: componente de detergentes e } \\
\text { cosméticos pode dar origem a substâncias tóxicas }\end{array}$ & Ecotoxicologia & Nov/08 \\
\hline
\end{tabular}

Fonte: elaborado pelas autoras.

\section{Resultados e discussão}

Cabe destacar que apresentamos: dois TDC para exemplificar os traços de cientificidade, três para exemplificar os traços de didaticidade e dois para os traços de laicidade. Contudo, esse fato não indica que os textos escolhidos para exemplificar os traços de cientificida- 
Queiroz, S. L.; Ferreira, L. N. A.

de, por exemplo, apresentam apenas elementos relacionados a essa categoria, uma vez que elementos de didaticidade e laicidade também podem ser encontrados nesses textos, embora com menor frequência. Salienta-se também que esta discussão não se refere à identificação completa dos traços de cientificidade, didaticidade e laicidade de cada um dos textos selecionados, mas, de acordo com os objetivos do presente manuscrito, à apresentação dos principais aspectos presentes nesses textos que evidenciam tais traços. O Quadro 2 apresenta a relação dos textos selecionados e os traços discursivos predominantes em cada um deles. A discussão e exemplificação de cada uma das características são explicitadas a seguir.

\section{Artigos com predomínio de traços de cientificidade}

Pautamos a discussão dos traços de cientificidade nas seguintes características presentes nos TDC indicados no Quadro 1 pelos números 1 e 2:

- Aspectos característicos da atividade científica;

- Aspectos implícitos da atividade científica;

- Alta densidade discursiva;

- Recuperação de conhecimentos tácitos;

- Busca de credibilidade;

- Elementos de cientificidade nos recursos visuais.

O TDC indicado pelo número 2 (Quadro 1), "Catalisadores - em busca de estruturas de superfície", ë de autoria de P. R. J. Silva e H. Saitovitch - do Centro Brasileiro de Pesquisas Físicas - e de I. S. Lopes e F. B. Passos - do Departamento de Engenharia Química da Universidade Federal Fluminense (SILVA et al., 2004). O artigo tem como temática principal a catálise heterogênea, especialmente a técnica usada para caracterizar estruturas de superfície de sistemas catalíticos. Na introdução do artigo, os autores trazem uma definição sobre catálise, apresentam um breve histórico sobre esse fenômeno, assim como sua importância, além de explicitarem como ocorre a catálise heterogênea. Em seguida, no tópico intitulado "Espionando a matéria", os autores descrevem, genericamente, todas as etapas da espectroscopia nuclear denominada CATDP, usada para caracterizar propriedades de sólidos. O segundo tópico ("Estrutura da superfície de catalisadores bimetálicos") consiste na especificação da técnica desenvolvida pelos autores do artigo, assim como os benefícios advindos desse estudo, de modo a justificá-lo. A seguir, evidenciamos os traços de cientificidade presentes nesse texto:

a) Aspectos característicos da atividade científica

Observamos um texto repleto de descrições de modelos, metodologias cientificas, processos de análise de dados e interpretação de resultados. Em [1] temos um trecho que exemplifica o momento no qual o autor apresenta o principal objetivo do artigo:

[1] Apresentamos aqui resultados obtidos a partir do emprego da espectroscopia nuclear denominada 'correlação angular tempo-diferencial perturbada' (CATDP). Ao lado de técnicas tradicionais na área, a CATDP pode contribuir para melhor conhecimento dos sistemas catalíticos. (SILVA et al., 2004, p. 28) 
Traços de cientificidade, didaticidade e laicidade ...

Quadro 2. Artigos relacionados à química e os seus traços de cientificidade, didaticidade e laicidade, destacados para discussão no presente artigo.

\begin{tabular}{|c|c|c|c|c|}
\hline & \multicolumn{2}{|l|}{ Título do artigo } & \multicolumn{2}{|c|}{ Traços predominantes } \\
\hline \multirow[t]{2}{*}{1} & \multirow[t]{2}{*}{ Eletricidade estática: onde ficam as cargas? } & \multirow{8}{*}{ 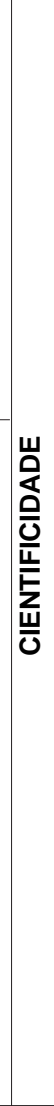 } & $\begin{array}{l}\text { Aspectos característicos da } \\
\text { atividade científica }\end{array}$ & $\begin{array}{l}\text { - Formulação de hipóteses } \\
\text { - Combinação de diferentes métodos } \\
\text { - Conclusões das pesquisas }\end{array}$ \\
\hline & & & $\begin{array}{l}\text { Aspectos implícitos da } \\
\text { atividade científica }\end{array}$ & $\begin{array}{l}\text { - Limitações dos cientistas } \\
\text { - Cooperação entre diferentes campos } \\
\text { de conhecimento } \\
\text { - Obtenção de patentes } \\
\text { - Financiamento de projetos de } \\
\text { pesquisa } \\
\text { - Controvérsias científicas } \\
\text { - Importância da aplicabilidade das } \\
\text { pesquisas }\end{array}$ \\
\hline \multirow[t]{6}{*}{2} & \multirow[t]{6}{*}{$\begin{array}{l}\text { Catalisadores: em busca de estruturas de } \\
\text { superfície }\end{array}$} & & $\begin{array}{l}\text { Aspectos característicos da } \\
\text { atividade científica }\end{array}$ & $\begin{array}{l}\text { - Descrições de modelos, } \\
\text { metodologias científicas, processos de } \\
\text { análise de dados e interpretação de } \\
\text { resultados }\end{array}$ \\
\hline & & & $\begin{array}{l}\text { Aspectos implícitos da } \\
\text { atividade científica }\end{array}$ & $\begin{array}{l}\text { - Ciência como um campo } \\
\text { multidisciplinar } \\
\text { - Ciência em constante } \\
\text { aperfeiçoamento } \\
\text { - Limitação de técnicas científicas } \\
\text { - Relação entre os processos da } \\
\text { ciência e seus produtos }\end{array}$ \\
\hline & & & \multicolumn{2}{|l|}{ Alta densidade discursiva } \\
\hline & & & \multicolumn{2}{|c|}{ Recuperação de conhecimentos tácitos } \\
\hline & & & Busca de credibilidade & - Nomeação \\
\hline & & & $\begin{array}{l}\text { Elementos de cientificidade } \\
\text { nos recursos visuais }\end{array}$ & $\begin{array}{l}\text { - Representações esquemáticas } \\
\text { - Gráficos } \\
\text { - Representação molecular }\end{array}$ \\
\hline 3 & $\begin{array}{l}\text { Nanociência e nanotecnologia: o gigantesco } \\
\text { e promissor mundo do muito pequeno }\end{array}$ & \multirow{6}{*}{ 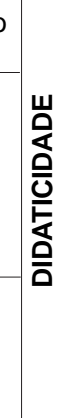 } & \multicolumn{2}{|l|}{ Interlocução direta com o leitor } \\
\hline \multirow{2}{*}{4} & \multirow{3}{*}{ Energia verde } & & Procedimentos explicativos & - Definição \\
\hline & & & \multicolumn{2}{|l|}{ Parágrafos sintetizadores } \\
\hline & & & $\begin{array}{l}\text { Elementos de didaticidade } \\
\text { nos recursos visuais }\end{array}$ & $\begin{array}{l}\text { - Representações esquemáticas } \\
\text { - Equações químicas } \\
\text { - Fórmulas matemáticas }\end{array}$ \\
\hline \multirow[t]{2}{*}{5} & \multirow[t]{2}{*}{ A química do cosmo } & & Figuralidade do ethos & $\begin{array}{l}\text { - Tessitura lexical } \\
\text { - Traços de envolvimento }\end{array}$ \\
\hline & & & \multicolumn{2}{|l|}{ Aspeamento } \\
\hline \multirow[t]{4}{*}{6} & \multirow{4}{*}{$\begin{array}{l}\text { A química na padaria: o açúcar nos pães } \\
\text { dietéticos }\end{array}$} & \multirow{4}{*}{ 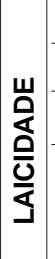 } & \multicolumn{2}{|c|}{ Natureza do artigo: relação direta com a vivência do leitor } \\
\hline & & & \multicolumn{2}{|l|}{ Tom de alerta ao leitor } \\
\hline & & & \multicolumn{2}{|c|}{ Impacto científico expresso no subtítulo } \\
\hline & & & $\begin{array}{l}\text { Elementos de laicidade nos } \\
\text { recursos visuais }\end{array}$ & $\begin{array}{l}\text { - Representação molecular } \\
\text { - Esquema } \\
\text { - Ilustrações que remetem ao cotidiano }\end{array}$ \\
\hline \multirow[t]{2}{*}{7} & \multirow{2}{*}{$\begin{array}{l}\text { Solução biode(sa)gradável: componente de } \\
\text { detergentes e cosméticos pode dar origem a } \\
\text { substâncias tóxicas }\end{array}$} & & \multicolumn{2}{|l|}{ Busca de credibilidade } \\
\hline & & & \multicolumn{2}{|l|}{ Simplificações } \\
\hline
\end{tabular}

Fonte: elaborado pelas autoras.

953

Ciênc. Educ., Bauru, v. 19, n. 4, p. 947-969, 2013 
Queiroz, S. L.; Ferreira, L. N. A.

Outra menção que caracteriza fortemente a cientificidade do TDC é aquela feita pelo autor à técnica utilizada para caracterizar estruturas de superfície de sistemas catalíticos:

[2] A CATDP é uma espectroscopia nuclear utilizada atualmente para caracterizar propriedades de sólidos. (SILVA et al., 2004, p. 28)

Em [3], [4] e [5] apresentamos trechos do texto que exemplificam a sequência descrita pelo autor referente à metodologia científica tratada:

[3] [...] é necessário introduzir, química e/ou metalurgicamente, na rede cristalina da amostra em estudo os chamados isótopos-sonda... (SILVA et al., 2004, p. 28)

[4] Esses isótopos-sonda, adequados para a CATDP, são introduzidos em grande número (aproximadamente 100 bilhões) na amostra em estudo. (SILVA et al., 2004, p. 28)

[5] Essas radiações, invisíveis e sem carga elétrica, são detectadas e, com auxílio de equipamento adequado, 'transfiguradas' em pulsos eletrônicos que podem ser devidamente conformados e registrados. (SILVA et al., 2004, p. 28)

Conforme explicitado anteriormente, no segundo tópico, o autor passa a tratar de uma metodologia científica específica, de modo a mostrar, ao leitor, uma aplicação prática da mesma. Por conseguinte, é nesse tópico que encontramos pontos que evidenciam a análise de dados [6] e a interpretação de resultados [7]:

[6] Ao se realizar o experimento CATDP para o catalisador Pt-In/ $\mathrm{Nb}_{2} \mathrm{O}_{5}$ [...], ficou evidenciada, conforme o ajuste dos dados experimentais, a presença do índio em diferentes estados [...]. (SILVA et al., 2004, p. 29)

[7] Tais experimentos, ambos realizados a $500^{\circ} \mathrm{C}$, permitiram explicar o efeito benéfico da adição de índio como promotor de catalisadores $\mathrm{Pt} / \mathrm{Nb}_{2} \mathrm{O}_{5}$ na reação de conversão do n-heptano [...]. (SILVA et al., 2004, p. 29)

b) Aspectos implícitos da atividade científica

Foram também identificados, no texto, elementos de cientificidade que configuram aspectos implícitos da atividade científica. O primeiro exemplo que apresentamos refere-se à ciência como um campo multidisciplinar, colocada pelo autor:

[8] Hoje os catalisadores são produtos de alta tecnologia, cujo estudo e desenvolvimento dependem de conhecimentos multidisciplinares nas 
áreas da física e química, e requerem apurado instrumental para a sua caracterização. (SILVA et al., 2004, p. 28)

Também são encontrados aspectos atinentes à ciência em constante aperfeiçoamento, ou seja, os conhecimentos científicos não são definitivos, mas constantemente melhorados a partir do desenvolvimento dos estudos. No TDC em foco, este aspecto é visualizado especialmente quando o autor relata que a definição sobre o termo 'catálise' sofreu modificações:

[9] Essa conceituação moderna de catálise é um desenvolvimento da definição proposta em 1901 pelo químico alemão Wilhelm Ostwald (1853-1932). (SILVA et al., 2004, p. 28)

A limitação de técnicas cientificas é outro ponto, tocado no artigo, que constitui aspectos implícitos da prática científica, e mostra, ao leitor, que as etapas e os instrumentos das pesquisas científicas são passíveis de falhas, conforme ilustra o trecho a seguir:

[10] A CATDP é uma [...]. Como toda técnica experimental, tem suas peculiaridades, limitações e exigências. (SILVA et al., 2004, p. 28)

Outro ponto digno de nota, relativo a essa dimensão, é a relação entre os processos da ciência e seus produtos, como a aplicação direta de um resultado da ciência:

[11] Essa reação foi utilizada como modelo para o processo industrial de produção de olefinas, matéria-prima para a produção de detergentes biodegradáveis. (SILVA et al., 2004, p. 29)

Esses exemplos constituem aspectos típicos da atividade científica importantes de serem apresentados aos estudantes, pois demonstram que tal atividade é fruto de uma construção humana, necessita de incentivos para ser posta em prática e tem aplicações na vida das pessoas. A explicitação de tais características da natureza da ciência tem o potencial de favorecer o atendimento de recomendações curriculares, que evidenciam a necessidade de se levarem tais aspectos aos alunos, de modo a evitar a formação de concepções equivocadas a esse respeito.

c) Alta densidade discursiva

Outro ponto marcante do texto em questão, que bem evidencia sua cientificidade, é a grande presença de termos técnicos e científicos, descrições de técnicas e mecanismos de ação de substâncias, jargões da área, entre outros:

[12] [...] inicia-se com a detecção das radiações $\gamma$ e passa ao registro da taxa de coincidência dessas radiações provenientes do decaimento do isótopo-sonda, o que permite extrair as freqüências das interações hiperfinas. (SILVA et al., 2004, p. 29) 
Queiroz, S. L.; Ferreira, L. N. A.

Zamboni (2001), tomando emprestadas colocações feitas por Peytard (1984 apud ZAMBONI, 2001), afirma que uma noção importante para se compreenderem questões relacionadas à divulgação científica é a de densidade discursiva. Esta é capaz de nos sugerir os motivos pelos quais certos documentos científicos parecem inexpugnáveis à vulgarização. Segundo essa noção, os documentos científicos são discursos de "alta densidade". Isso quer dizer que, no texto científico, nem tudo é passível de reformulação. Segundo a autora, no TDC, essa "alta densidade" pode se manifestar por meio de axiomas, teoremas, operações do discurso matemático, que aparecem na forma de um conjunto de termos-chave imutáveis e universais. Dessa forma, a densidade do discurso científico reside no nível dos conceitos e das relações estruturais fundamentais.

d) Recuperação de conhecimentos tácitos

Identificamos também, no texto em foco, uma característica bastante comum em artigos científicos: a presença de conhecimentos tácitos. Estes são definidos por Zamboni (2001, p. 99) como "aqueles sobre os quais não cabe mais sujeitar a comprovação ou contestação". Ou seja, trata-se de termos ou expressões tão consolidadas na comunidade científica que não necessitam de definição. A seguir, apresentamos exemplos retirados do TDC em questão:

[13] Uma importante classe de catalisadores heterogêneos é o 'catalisador metálico suportado', cuja configuração básica apresenta sítios ativos [...] dispersos em um suporte, em geral um óxido metálico poroso. (SILVA et al., 2004, p. 26-27).

Em contrapartida, percebemos uma estratégia discursiva acionada pelo autor, em várias passagens do texto, com o intuito de recuperar tais conhecimentos, como nos exemplos a seguir:

[14] [...] cuja concentração básica apresenta sítios ativos (átomos metálicos responsáveis pela atividade catalítica) dispersos em um suporte [...]. (SILVA et al., 2004, p. 26-27)

[15] Essa liberação de energia pode se dar em várias etapas, configurando uma 'cascata nuclear', ou seja, o núcleo emite radiações ã até atingir seu estado base-estável. (SILVA et al., 2004, p. 28)

Os conhecimentos tácitos estão implicados no entendimento do tema central do texto, cujo domínio, se compartilhado pelo autor e seus pares, não necessita de explicações, mas, se esse domínio está supostamente ausente do núcleo de conhecimento pressuposto dos destinatários, tais recuperações fazem-se necessárias para a compreensão do texto. Segundo Zamboni (2001), está aí, em funcionamento, uma representação do destinatário a partir da imagem que faz dele o enunciador.

Como é possível observar nos exemplos [14] e [15], a inserção desse tipo de procedimento se deu por meio de inserções parentéticas [14] e aposição [15]. Tanto as inserções parentéticas como a aposição (uso de aposto) representam rupturas que o segmento inserido 
provoca no trecho que o precede e no que o segue (ZAMBONI, 2001). Consideramos que a inserção desses recursos ajuda a compor a representação de um leitor que necessita, para levar a cabo a leitura de um texto, intercalar momentos de densidade - nos quais a ciência toma a $\mathrm{vOz}$ - e momentos de leveza - nos quais os recursos explicativos tomam espaço.

e) Busca de credibilidade

Outra característica de cientificidade que elencamos é a busca de credibilidade. Esse recurso se deu no texto em pauta, do ponto de vista formal, por meio do uso do recurso da nomeação, que consiste em inserções acompanhadas de fórmulas metalinguísticas do tipo: o processo chamado de... a teoria chama de x... os cientistas denominam de x... etc. Vejamos exemplo desse recurso a seguir:

[16] O conteúdo dessas informações se refere às interações (denominadas hiperfinas) que ocorrem entre os momentos nucleares do isótopo-sonda [...]. (SILVA et al., 2004, p. 28)

É possível observar, no caso apresentado, que o segmento discursivo que antecede o termo nomeado está numa formulação que não é a científica, na tentativa do enunciador de aproximar o leigo do que vai ser tratado; após isso, o termo científico é inserido através do recurso da nomeação. De acordo com Zamboni (2001), essa remissão ao discurso científico é uma garantia de confiabilidade que o próprio dizer adquire diante dos leitores.

f) Elementos de cientificidade nos recursos visuais

Traços de cientificidade também podem ser observados nos recursos visuais do texto. Tal aspecto ficou evidenciado nas quatro figuras apresentadas no artigo. As duas primeiras figuras constituem representações esquemáticas: a primeira representa um esquema de um catalisador metálico, e a segunda, a detecção obtida pela espectroscopia CATDP. As demais figuras apresentam gráficos correspondentes a resultados dos estudos concernentes ao texto. Também é digna de nota a representação molecular que se encontra sob o título do TDC, ocupando página dupla, a qual apresenta um esquema de moléculas reagentes distribuídas em um sítio ativo de catalisador, ilustrando o conteúdo do texto.

O TDC indicado pelo número 1 (Quadro 1), "Eletricidade estática: onde ficam as cargas?”, é de autoria de F. Galembeck, A. F. Ramos e R. F. Gouveia, do Instituto de Química da Universidade Estadual de Campinas e do Instituto do Milênio de Materiais Complexos (GALEMBECK; RAMOS; GOUVEIA, 2004). O artigo inicia-se com uma breve definição sobre os fenômenos eletrostáticos, passando ao segundo tópico ("Elétrons, íons ou ambos?”), o qual dá prosseguimento às conceituações e definições de termos relacionados ao tema. $\mathrm{O}$ tópico seguinte ("Ignorância problemática") coloca o problema principal do artigo: o fato de não serem conhecidas as causas da eletricidade estática em diversos materiais. Entre o terceiro e o penúltimo tópico ("Acidentes e desastres", "Questão mais desafiadora”, "Kelvin mais força atômica", "Interior e casca", "O que já aprendemos" e "Formulando hipóteses", respectivamente), temos descrições das teorias relacionadas aos avanços já feitos na área e às hipóteses mais prováveis de resolução do problema. O último tópico apresenta uma aplicação dos estudos desenvolvidos. No texto encontram-se várias características que evidenciam traços de 
Queiroz, S. L.; Ferreira, L. N. A.

cientificidade, que complementam aqueles exemplificados na análise do TDC indicado pelo número 2 (Quadro 1).

a) Aspectos característicos da atividade científica

Inicialmente, destacamos os relatos dos autores concernentes às pesquisas por eles desenvolvidas. Nesses relatos, observamos a formulação de hipóteses [17], a combinação de diferentes métodos [18] e as conclusões das pesquisas [19]:

[17] Assim, para levar o trabalho adiante, precisamos formular novas hipóteses de trabalho. (GALEMBECK; RAMOS; GOUVEIA, 2004, p. 39)

[18] Esse resultado concorda muito bem com o que é obtido no mapa de potenciais elétricos das mesmas partículas, usando-se a microscopia de varredura de potenciais elétricos, ou seja, a combinação do método de Kelvin com um microscópio de força atômica. (GALEMBECK; RAMOS; GOUVEIA, 2004, p. 37)

[19] Graças a isso, aprendemos que não há uma solução geral para a natureza e identidade dos portadores de cargas nos plásticos: ela deve ser descoberta experimentalmente em cada material [...]. (GALEMBECK; RAMOS; GOUVEIA, 2004, p. 37)

b) Aspectos implícitos da atividade científica

Diversos trechos também revelam aspectos característicos da atividade científica, de certo modo implícitos ou pouco conhecidos pelo público em geral, como as limitações dos cientistas, as dificuldades por eles enfrentadas [20] e a cooperação entre diferentes campos de conhecimento [21]:

[20] Essa nossa ignorância cria vários problemas tecnológicos... (GALEMBECK; RAMOS; GOUVEIA, 2004, p. 34)

[21] Essa hipótese baseia-se em algumas informações que vêm de outras áreas de pesquisa. (GALEMBECK; RAMOS; GOUVEIA, 2004, p. 39)

No texto são encontrados elementos que bem caracterizam a práxis científica, como a obtenção de patentes [22] e o financiamento de projetos de pesquisa [23]:

[22] Essa aplicação de cargas negativas do látex é o assunto de uma patente da Unicamp [...]. (GALEMBECK; RAMOS; GOUVEIA, 2004, p. 39) 
Traços de cientificidade, didaticidade e laicidade ...

[23] [...] e está sendo explorada em um projeto da empresa [...]. (GALEMBECK; RAMOS; GOUVEIA, 2004, p. 39)

Identificamos, também, alguns trechos que se referem às controvérsias científicas [24] e à importância da aplicabilidade dessas pesquisas [25]:

[24] [...] não há qualquer consenso quanto à natureza dos portadores de cargas em dielétricos e esta permanece como um grande desafio ao conhecimento científico atual [...]. (GALEMBECK; RAMOS; GOUVEIA, 2004, p. 36)

[25] É muito importante procurarmos aplicar toda a ciência que vamos adquirindo através da pesquisa. Os projetos executados no laboratório dos autores deste artigo, na Unicamp, já geraram pelo menos uma aplicação importante, que é a produção de plásticos coloridos com corantes básicos. (GALEMBECK; RAMOS; GOUVEIA, 2004, p. 39)

\section{Artigos com predomínio de traços de didaticidade}

Pautamos a discussão dos traços de didaticidade nas seguintes características presentes nos TDC indicados no Quadro 1 pelos números 3, 4 e 5:

- Procedimentos explicativos;

- Parágrafos sintetizadores;

- Elementos de didaticidade nos recursos visuais;

- Figuralidade do ethos;

- Aspeamento;

- Interlocução direta com o leitor.

O TDC indicado pelo número 4 (Quadro 1), "Energia verde", de autoria de J. F. de Carvalho, do Programa Interunidades de Pós-Graduação em Energia da Universidade de São Paulo (CARVALHO, 2006), trata do aproveitamento da energia solar para a obtenção de combustíveis derivados de vegetais, como forma alternativa aos combustíveis fósseis. Por isto, são também abordados, no artigo, aspectos econômicos e políticos, ligados a questões ambientais.

$\mathrm{O}$ autor coloca, inicialmente, as formas de aproveitamento da energia solar, e explica o significado de "energia verde", além de mostrar exemplos de suas formas de obtenção e produtos. Em seguida, passa a apresentar valores numéricos com o objetivo de informar, ao leitor, sobre a grande quantidade de energia solar que chega à Terra, acompanhados de cálculos de aproveitamento, com a finalidade de apresentar uma espécie de balanço da energia proveniente do Sol na Terra.

Após essa parte introdutória, o autor passa a estreitar o tema tratado no artigo. Assim, abre subtópicos intitulados "Fotossíntese e vida", "Eficiência da fotossíntese" e "Plantações de energia". No primeiro, é feita uma descrição detalhada da reação de fotossíntese, o que inclui definições, descrição das substâncias envolvidas e reações químicas que formam suas etapas. No segundo tópico, o autor se dedica a descrever as etapas dos cálculos de eficiência da reação de fotossíntese. No terceiro tópico, é enumerada uma série de vantagens do uso da 
Queiroz, S. L.; Ferreira, L. N. A.

energia verde, embasado em aspectos de ordem econômica, social, política e ambiental. A seguir, apresentamos as características que evidenciam os traços de didaticidade presentes no texto em questão:

a) Procedimentos explicativos

Percebemos um texto repleto de conceituações, representações químicas e fórmulas matemáticas, o que muito nos remeteu a um texto didático. Pode-se perceber o discurso didático na fala do autor em diversos trechos, o qual lançou mão de recursos metalinguísticos, como no exemplo a seguir:

[26] Essa energia (E) é obtida multiplicando-se a frequência da radiação (v) por uma constante invariável de proporcionalidade, a constante de Planck (h), cujo valor é 6,63 x $10^{-34}$ joules-segundo. (CARVALHO, 2006, p. 31)

Entendemos que os procedimentos explicativos das mais diversas ordens representam estratégias discursivas acionadas pelo enunciador com o intuito de atrair e manter o leitor interessado em toda a extensão do texto. Segundo Zamboni (2001), os procedimentos explicativos são entradas de segmentos de natureza explicativa no texto, correspondendo a uma ação didática e educativa de compartilhar os saberes nele expostos. Do ponto de vista formal, a inserção desse tipo de procedimento se deu no texto analisado, sobretudo através de inserções parentéticas e por aposição.

[27] A radiação emitida pelo Sol e que chega à superfície da Terra pode ser aproveitada tanto diretamente, em coletores solares (que aquecem água e outros fluidos) e em células fotovoltaicas (que geram energia elétrica), quanto indiretamente, sob a forma de 'energia verde'. (CARVALHO, 2006, p. 28)

[28] O biodiesel, formado através do processo de transesterificação, tem como fonte qualquer óleo vegetal... (CARVALHO, 2006, p. 33)

Como era de se esperar, por sua natureza didática, o recurso da definição foi bastante utilizado pelo autor. A seguir, apresentamos alguns exemplos:

[29] A energia solar que alcança o nosso planeta é calculada em função da chamada constante solar - a potência com que a radiação solar incide sobre uma superfície perpendicular à sua direção de propagação, fora da atmosfera terrestre, em seus limites extremos. (CARVALHO, 2006, p. 28)

[30] Plantas como o aguapé [...] permitem a produção, por digestão anaeróbica (decomposição por bactérias, sem a presença de oxigênio), do gás metano. (CARVALHO, 2006, p. 33) 
Em [29], o mecanismo da aposição cumpre a função de definição. Em [30], a função da definição é exercida pela inserção parentética. Em [29], temos um exemplo que ilustra uma estratégia usada pelo autor no decorrer de todo o texto: a definição por conceituação, na qual o termo científico é conceituado para ser mais bem compreendido. De acordo com Zamboni (2001), a conceituação é um recurso de necessária utilização para se identificar fenômenos naturais e criar objetos de ciência. Em [30], ocorre a definição por justaposição metalinguística, na qual o termo "digestão anaeróbica" é definido ao mesmo tempo que é usado para compor a informação do parágrafo. Ou seja, "a justaposição do segmento explicitador ocorre por fórmulas metalinguísticas introdutórias" (ZAMBONI, 2001, p. 137). Segundo a autora, essas formas assumem uma dupla função, na qual, ao mesmo tempo em que se mostra o objeto, fazse uso dele.

b) Parágrafos sintetizadores

Observamos, também, que os parágrafos que finalizam os tópicos com maior grau de densidade discursiva apresentam um resumo que, de certa forma, possibilita ao leitor ter uma ideia geral - e com fins mais práticos - dos parágrafos anteriores. Em [31], temos o trecho que finaliza uma sequência de parágrafos com a descrição de cálculos referentes ao balanço da energia solar que chega à Terra. Em [32], apresentamos o trecho conclusivo subsequente aos cálculos discorridos no texto a respeito da eficiência da reação de fotossíntese:

[31] Assim, o total de energia solar incidente equivale à soma das energias reemitidas, equilibrando o balanço. (CARVALHO, 2006, p. 30)

[32] Isso significa que, na escala molecular, e no que diz respeito à absorção dos quanta de luz, a eficiência termodinâmica líquida da fotossíntese é de 112/336, o que é igual a 0,33 (ou seja, 33\%). (CARVALHO, 2006, p. 32)

c) Elementos de didaticidade nos recursos visuais

São encontradas quatro figuras, três delas correspondem a representações esquemáticas que ilustram trechos do texto. Inicialmente, podemos citar o uso de três representações esquemáticas colocadas pelo autor. Consideramos essa estratégia do autor, feita a partir da representação que faz de seu destinatário, como uma forma de tornar pontos de alta densidade discursiva, presentes no texto - como a descrição das etapas da fotossíntese e os cálculos de sua eficiência de reação -, mais compreensíveis. Ao longo do texto, também estão dispostas equações químicas que representam as etapas da reação de fotossíntese, além do uso de fórmulas matemáticas, evidenciando fortes traços de didaticidade no TDC.

Com o intuito de apresentar, ao leitor, todas as características de didaticidade identificadas nos TDC analisados, discutimos, também, os resultados provenientes da análise do texto indicado pelo número 5 (Quadro 1), "A química do cosmo", de autoria de M. E. Varela, do Complexo Astronômico El Leoncito, Argentina (VARELA, 2007). Sua temática envolve a 'memória química' de meteoritos, capaz de fornecer informações importantes no entendimento sobre a evolução da galáxia.

O TDC se refere, inicialmente, aos objetos de estudo do campo da cosmoquímica. No segundo tópico (“Grande segredo"), a autora aborda como se determina a abundância dos 
Queiroz, S. L.; Ferreira, L. N. A.

elementos químicos no Sol; e, no terceiro ("De onde vêm os elementos?"), descreve-se onde e como se produzem esses elementos. No terceiro tópico ("Massas fracionadas"), a autora traz definições sobre o átomo; e, no tópico "Mensagem da nebulosa", são abordados aspectos relacionados ao chamado 'fracionamento terrestre'. O penúltimo tópico ("Grãos pré-solares") apresenta a forma como são obtidas informações sobre a 'poeira interestelar'; e, no último ("Pedacinhos de estrelas"), é discutido como o material que forma os meteoritos foi processado no sistema solar.

Verificamos que o artigo apresenta uma abordagem essencialmente conceitual, no qual é feita uma descrição a respeito do campo de conhecimento em questão, sua importância e aplicações. O TDC apresenta uma linguagem bastante acessível e, embora trate de um assunto com certa densidade discursiva, é colocado de forma compreensível ao seu interlocutor, por meio de várias estratégias discursivas acionadas pela autora:

d) Figuralidade do ethos

O texto manifesta uma característica do discurso da divulgação científica relacionada ao modo de enunciação, identificada por Maingueneau (1997) como o tom do discurso. Para esse autor, o que é dito e o tom com que é dito constituem parte integrante da formação discursiva. Dessa forma, percebemos, no TDC analisado, que o autor intercala a linguagem científica com exemplos de coloquialismos, deixando transparecer uma atitude espontânea com a linguagem:

[33] Em outras palavras, nos meteoritos e demais objetos extraterrestres, permanecem características relativas ao ambiente em que eles se formaram. Basta a nós encontrá-las. (VARELA, 2007, p. 19)

$\mathrm{O}$ autor fez uso de comparações para facilitar o entendimento do leitor com relação às pesquisas sobre a evolução química da galáxia, mediante o estudo de meteoritos. Ao longo dessa descrição, verificamos que se alternam trechos com termos técnicos específicos da área com trechos explicativos:

[34] Aqueles que chegam ao solo - muitos são completamente 'queimados' na queda - passam a ser chamados meteoritos. (VARELA, 2007, p. 19)

[35] O estudo das pequenas variações das massas dos isótopos (o chamado fracionamento de massas) é outra ferramenta empregada pela cosmoquímica para extrair de um meteorito sua 'memória' química. (VARELA, 2007, p. 21)

Tais recursos deixam transparecer, por parte do autor, uma atitude peculiar com a linguagem e, em especial, com as palavras, às quais é dada um tom de leveza, reconhecido por Zamboni (2001) como tessitura lexical. Outra característica referente ao tom do discurso, empregado pelo autor, presente no texto são os traços de envolvimento colocados por ele na forma de exclamações ou impressões pessoais:

962

Ciênc. Educ., Bauru, v. 19, n. 4, p. 947-969, 2013 
[36] A cosmoquímica está em constante evolução, e seus modelos se adaptam aos novos dados que os meteoritos, como testemunhas privilegiadas dos primeiros instantes da formação do sistema solar, nos vão aos poucos entregando. (VARELA, 2007, p. 23)

e) Aspeamento

Percebemos, também, o uso frequente, pelo autor, de aspas. De acordo com Zamboni (2001), esse recurso pode ser utilizado com diversos objetivos. No texto em questão, percebemos que o aspeamento foi usado, sobretudo, nas comparações, como nas palavras "queimados" e "memória", exemplificadas nos fragmentos [34] e [35]. Zamboni (2001) alerta que se deve notar que o aspeamento em TDC ocorre tanto no termo técnico-científico, como nas palavras coloquiais.

Acreditamos que a presença dessas marcas de envolvimento do autor constitui parte de sua estratégia comunicacional de facilitar a compreensão do texto, tornando-o, além disso, convidativo à leitura. Com o intuito de discutir os últimos exemplos característicos de didaticidade, apresentamos, ainda, a análise do TDC indicado pelo número 3 (Quadro 1), "Nanociência e Nanotecnologia: o gigantesco e promissor mundo do muito pequeno", de autoria de H. E. Toma e K. Araki, do Laboratório de Química Supramolecular e Nanotecnologia do Instituto de Química, da Universidade de São Paulo (TOMA; ARAKI, 2005).

O texto aborda a temática da nanociência e nanotecnologia, com enfoque para alguma das perspectivas que estão surgindo com o desenvolvimento de estudos da área. Trata, inicialmente, de definições sobre o assunto, no qual é feito um resgate de teorias de outrora para proceder com as explicações e projeções das aplicações da área. No segundo tópico ("Contra o bom senso"), os autores discorrem sobre o fato de "no mundo nanométrico não haver espaço para a física clássica". Com essa ideia, os autores explicam, à luz da mecânica quântica, os motivos pelos quais colocam tal afirmação. No terceiro tópico ("Nano: partículas, fios e tubos"), são apresentadas as formas com as quais a nanotecnologia pode ser trabalhada, com suas aplicações. Nos próximos tópicos ("Estratégia supramolecular", "Incrível nanomáquina", "Dispositivos moleculares", "Como no cérebro", "Spin e computadores quânticos", respectivamente), tratam de vertentes da área, com definições e aplicações das mesmas. $\mathrm{O}$ último tópico ("Mais de um trilhão de dólares") discorre sobre os investimentos da área. A seguir, discutimos um traço de didaticidade ainda não abordado:

f) Interlocução direta com o leitor

Em [37], encontramos o recurso da interlocução direta com o leitor, sob a forma do que Zamboni (2001) denomina de segmentos de interpelação direta, que ocorrem sob a feição de perguntas apreciativas que são semelhantes à retórica didática, pois interpõem indagações no desenvolvimento da exposição, que, geralmente, são respondidas apenas pelo professor, no intuito de conduzir o raciocínio do aprendiz pela trilha desejada.

[37] Você, leitor, já pensou o que aconteceria se deixássemos de lado essa notável organização molecular e colocássemos, em um tubo de ensaio, todos os ingredientes químicos envolvidos na fotossíntese? Nem é preciso tentar: a luz não provocaria a fotossíntese, pois as transfor- 
Queiroz, S. L.; Ferreira, L. N. A.

mações seriam caóticas e improdutivas. Percebeu o significado da química supramolecular? (TOMA; ARAKI, 2005, p. 28)

Do mesmo modo, nesse exemplo, também podemos destacar o tom usado pelo enunciador, que inscreve sua maneira de dizer num tom de deslumbramento e surpresa. Segundo Zamboni (2001, p. 113), essa maneira de falar opera tanto no lugar do enunciador quanto do destinatário, "suscitando a impressão de que o leitor é convidado a experimentar as mesmas emoções vivenciadas pelo enunciador ao tomar conhecimento do tópico científico em questão".

\section{Artigos com predomínio de traços de laicidade}

Pautamos a discussão dos traços de laicidade nas seguintes características presentes nos TDC indicados no Quadro 1 pelos números 6 e 7 :

- Natureza do artigo: relação direta com a vivência do leitor;

- Tom de alerta ao leitor;

- Impacto científico expresso no subtítulo;

- Elementos de laicidade nos recursos visuais;

- Busca de credibilidade;

- Simplificações.

O TDC indicado pelo número 7 (Quadro 1), "Solução biode(as)gradável: componente de detergentes e cosméticos pode dar origem a substâncias tóxicas", de autoria de C. E. A. e Silva, S. A. C. de Souza e M. R. Miranda, do Instituto de Biofísica Carlos Chagas Filho da Universidade Federal do Rio de Janeiro (SILVA, SOUZA; MIRANDA, 2008), trata das discussões em torno do composto químico nonilfenóis-etoxilados, presente em alguns produtos de limpeza e cosméticos. Assim, o foco principal do artigo são as consequências ambientais e de saúde pública decorrentes da degradação biológica dos materiais que têm essa substância em sua composição.

Os autores tratam, inicialmente, do hábito de a sociedade humana usar produtos de limpeza e os motivos pelos quais os detergentes superaram os sabões comuns. Em seguida, passam a conceituar, brevemente, os detergentes e a abordar aspectos econômicos, ambientais e legais que emergiram a partir do aumento do consumo dos mesmos. O primeiro tópico do texto ("Diferentes aplicações"), como seu próprio nome indica, envolve uma descrição das diversas aplicações dos alquilfenóis-etoxilados (grupo do qual fazem parte os nonilfenóisetoxilados). Os dois tópicos subsequentes ("Degradação incompleta traz riscos" e "Prejuízo para o sistema hormonal") abordam, respectivamente, questões ambientais e de saúde ligadas aos produtos de degradação dos contaminantes nonilfenóis-etoxilados. O último tópico ("Controle é necessário") traz um alerta dos autores para a necessidade de controle de uso dessas substâncias.

Assim, o primeiro ponto que evidencia os traços de laicidade do TDC em questão é a sua própria natureza, uma vez que apresenta um assunto que tem relação e aplicação direta com a vivência do leitor. A seguir, apresentamos as demais características concernentes aos traços de laicidade presentes no artigo. 
a) Tom de alerta ao leitor

Também é digno de nota que o artigo apresenta várias consequências do desenvolvimento científico e a necessidade de mobilização por parte da sociedade. Dessa forma, acreditamos que uma característica relevante relacionada à categoria em foco é o serviço prestado, por cientistas/divulgadores, a seus leitores. Um ponto do texto que bem retrata essa questão está apresentado a seguir:

[38] O aumento dos estudos científicos sobre tais compostos, nas últimas décadas, parece não ser acompanhado pelos tomadores de decisões, demonstrando haver um lapso de informação entre esses setores da sociedade. (SILVA, SOUZA; MIRANDA, 2008, p. 23)

b) Impacto científico expresso no subtítulo

No que diz respeito aos recursos visuais e textuais, o texto vem apresentado em seis páginas. O título ocupa página dupla e vem destacado em letras grandes. Apresenta, também, um subtítulo, exibido na primeira página, com letras destacadas. A forma como a informação está exibida no subtítulo ("Componente de detergentes e cosméticos pode dar origem a substâncias tóxicas") é característica do discurso da divulgação científica. Nesse discurso é comum a procura pela relevância nas conclusões das pesquisas científicas e na aplicação de seus resultados no cotidiano das pessoas. Por esse motivo, os resultados do trabalho em questão são colocados no subtítulo com o tom de impacto, com o intuito de chamar a atenção do leitor para o texto. Segundo Zamboni (2001), a atitude de reserva e cautela que performatiza a enunciação do cientista na conclusão e avaliação de sua pesquisa é modificada para uma atitude de assertividade no TDC.

c) Elementos de laicidade nos recursos visuais

Como pano de fundo de todos esses elementos, há uma foto de um rio repleto de espumas, o que nos permite deduzir que se trata de um rio poluído por descarte de detergentes, e, também, proporciona uma apresentação do assunto do texto ao leitor. O texto propriamente dito é iniciado apenas no final da segunda página, ocupando uma pequena coluna na parte inferior direita, com a seguinte frase em destaque: "O uso de produtos de limpeza". Consideramos que esse destaque visual dado à primeira frase do texto está voltado para provocar, no leitor, a atitude de prosseguir na leitura, para saber mais sobre o que ela anuncia.

São encontradas apenas duas figuras, sendo uma representação molecular e um esquema. A primeira mostra a molécula de nonilfenol-etoxilado, exibida de forma bastante didática, com os átomos representados em cores diferentes. As cadeias também vêm contornadas, demonstrando mais uma estratégia do autor em favorecer a compreensão do leitor. Ademais, há um procedimento explicativo na legenda da figura reforçando essa estratégia. Na segunda figura, há um esquema que explica a ação do 4-nonilfenol no sistema hormonal. No decorrer do texto, também há figuras sem indicação: na terceira página, há uma foto de produtos de limpeza, sem legenda e, na última página, há a foto de uma estação de tratamento de esgotos com a seguinte legenda: 
Queiroz, S. L.; Ferreira, L. N. A.

[39] Os processos comumente utilizados nas estações de tratamento de esgotos não eliminam os subprodutos tóxicos gerados a partir dos nonilfenóis-etoxilados presentes em diversos produtos domésticos. (SILVA, SOUZA; MIRANDA, 2008, p. 23)

Consideramos que o uso da primeira foto representa, mais uma vez, a tentativa dos autores de aproximar o leitor do texto, uma vez que a foto de produtos de limpeza representa a característica de cotidianidade do mesmo. A segunda ilustra a informação da legenda que, mais uma vez, chama o leitor para a problemática tratada no artigo.

d) Busca de credibilidade

Para reforçar as informações colocadas, constatamos que os autores buscaram credibilidade em resultados de estudos feitos em outros países, a fim de corroborar suas afirmações:

[40] No Reino Unido, um estudo estimou que $83 \%$ dos nonilfenóisetoxilados produzidos chegam ao ambiente, e que $37 \%$ atingem ambientes aquáticos. (SILVA, SOUZA; MIRANDA, 2008, p. 21)

Esse assunto também é tratado segundo perspectivas legais, conforme ilustra o fragmento [41]. Mais uma vez, essas informações vêm reforçadas [42], indicando o artifício dos autores na busca de confiabilidade para suas assertivas:

[41] Mesmo restrito ou proibido em outros países, em função da toxicidade dos produtos formados pela sua degradação, no Brasil o uso dos nonilfenóis-etoxilados ainda é liberado. (SILVA, SOUZA; MIRANDA, 2008, p. 18)

[42] Os Estados Unidos também admitiram os riscos do nonilfenol e prepararam um guia recomendando limites de concentrações máximas [...]. (SILVA, SOUZA; MIRANDA, 2008, p. 22)

O TDC indicado pelo número 6 (Quadro 1), de autoria de F. A. P. Cunha, do Departamento de Química, da Universidade Federal da Paraíba, tem como título "A química na padaria: o açúcar nos pães dietéticos", e explora a importância do açúcar na fabricação do pão e contrasta com o fato de esse produto ser classificado como dietético (CUNHA, 2008). Na introdução do texto, o autor define brevemente o que são produtos dietéticos, tecendo algumas considerações sobre o açúcar e sua função no processo de panificação. No primeiro tópico ("Filme de glúten"), o autor fala sobre o glúten presente na farinha de trigo usada para fabricar o pão. No segundo tópico ("Receita básica"), o autor apresenta a receita básica para o pão de forma e explicita a função de cada um dos ingredientes. No terceiro tópico ("Esquentando as massas"), são colocados critérios para a produção de pães com boa qualidade. Nos tópicos seguintes ("Produzindo gás", "Regra de três", "Sem açúcar" e "Temperatura máxima”), são apresentados critérios para a confecção de pães com um mínimo de resíduo de açúcar. A seguir, discutimos um traço de laicidade ainda não abordado:

966

Ciênc. Educ., Bauru, v. 19, n. 4, p. 947-969, 2013 
e) Simplificações

Recursos de simplificação estão presentes no texto em pauta, conforme exemplifica o fragmento a seguir:

[43] O 'R' da equação é a constante universal dos gases e vale 0,082 (para nossos propósitos aqui, podemos ignorar suas unidades). (CUNHA, 2008, p. 38)

Percebemos que a expressão omite outras informações que, na percepção do enunciador, seriam de difícil compreensão para o leitor representado por ele. Em [44], a analogia cumpre essa função de simplificação:

[44] Chegamos ao valor $\mathrm{n}=0,0088 \mathrm{~mol}$ (posto de modo simples, o 'mol' é uma quantidade numérica fixa de matéria, assim como um cento de laranjas tem a massa diferente de um cento de limões; no caso do gás carbônico, $\mathrm{CO}_{2}$, ela vale 44 gramas). (CUNHA, 2008, p. 38)

Os traços de laicidade apresentados evidenciam a representação que o enunciador faz de um destinatário que necessita receber um conhecimento que presumidamente não tem.

\section{Considerações finais}

A partir da análise realizada, constatamos que as considerações de Zamboni (2001) se adequaram aos propósitos do trabalho aqui apresentado, uma vez que permitem ao leitor especialmente aquele interessado no uso de TDC como recurso didático - ampliar o seu olhar no sentido de perceber as intenções dos enunciadores através dos recursos discursivos colocados em suas produções.

Verificamos uma variedade de abordagens nos TDC, fato que evidencia sua abrangência e as possibilidades de aprendizagem que representam. Observamos ainda que a linguagem empregada na maior parte deles é acessível e, quando isso não ocorre ou quando não se faz possível pela alta densidade discursiva inerente ao discurso científico, uma série de estratégias é acionada pelos autores para aproximar o leitor do texto e facilitar sua compreensão.

Constatamos que os traços de cientificidade, laicidade e didaticidade aparecem em graus variados nos TDC analisados. Em alguns deles, um desses traços sobressai aos demais, e, em outros, há um equilíbrio desses traços. Acreditamos que essas variações ocorrem de acordo com a natureza do assunto tratado no artigo, com os objetivos dos autores e da representação que fazem de seus destinatários.

É importante considerar, no entanto, as condições de produção dos autores desses textos. Embora estejam condicionados às normas editoriais da revista em pauta, consideramos, à luz do referencial teórico adotado, que o autor elabora com a intenção de provocar, em seu leitor, as reações desejadas, ou seja, o locutor projeta nos recursos discursivos da língua com o intuito de gerar um efeito de sentido. Esse fato ancora-se, especialmente, na noção de formação imaginária, definida por Pêcheux (1997) e elencada por Zamboni (2001), a qual tem 
Queiroz, S. L.; Ferreira, L. N. A.

grande validade para explicitar a natureza discursiva e linguística do discurso da divulgação científica.

Consideramos que os resultados provenientes da identificação dos traços de cientificidade, didaticidade e laicidade se traduzem em um importante artifício para o professor de química. A partir do entendimento de tais traços, o professor poderá ter suavizado o seu trabalho na escolha de TDC mais adequados aos seus objetivos educacionais. Nessa perspectiva, aquele que desejar, por exemplo, promover a contextualização de um determinado assunto em sala de aula poderá escolher um TDC que apresente um elevado grau de laicidade, uma vez que estes manifestam diversas relações do assunto tratado no artigo com o cotidiano do leitor. Em contraponto, aquele que desejar promover um melhor entendimento sobre a natureza da ciência, poderá escolher os TDC com alto grau de cientificidade, uma vez que estes primam por revelar aspectos característicos da atividade científica, tanto implícitos quanto explícitos. Por conseguinte, o professor que pretender trabalhar certos conceitos com seus alunos e preferir apresentá-los de maneira diferenciada, em uma linguagem acessível, aliada a recursos didáticos atrativos, terá, nos TDC com alto grau de didaticidade, tal possibilidade. Ao professor será possível, ainda, aliar diferentes objetivos ao optar por TDC que apresentam equilíbrios de traços de cientificidade, didaticidade ou laicidade.

Portanto, os resultados alcançados nos permitem sugerir que os TDC analisados constituem um material conveniente para os professores que optarem por: diversificar suas aulas, promover o desenvolvimento de visões amplas sobre assuntos científicos, e apresentar uma imagem mais ajustada sobre o processo de construção da ciência.

\section{Referências}

CARVAlHO, J. F. Energia verde. Ciência Hoje, São Paulo, v. 39, n. 232, p. 28-33, 2006.

CUNHA, F. A. P. A química na padaria: o açúcar nos pães dietéticos. Ciência Hoje, São Paulo, v. 42, n. 247, p. 34-39, 2008.

GALEMBECK, F. G.; RAMOS, A. F.; GOUVEIA, R. F. Eletricidade estática: onde ficam as cargas? Ciência Hoje, São Paulo, v. 2, n. 208, p. 32-39, 2004.

IVANISSEVICH, A. Ciência fora do casulo. Ciência Hoje, São Paulo, v. 31, n. 184, p. 24-25, 2002.

MAINGUENEAU, D. Novas tendências em análise do discurso. Campinas: Pontes, 1997.

MARTINS, I.; NASCIMENTO, T. G.; ABREU, T. B. Clonagem na sala de aula: um exemplo do uso didático de um texto de divulgação científica. Investigações em Ensino de Ciências, Porto Alegre, v. 9, n. 1, p. 95-111, 2004.

PÊCHEUX, M. Análise automática do discurso (AAD-69). In: GADET, F.; HAK, F. (Org.). Por uma análise automática do discurso: uma introdução à obra de Michel Pêcheux. Campinas: Pontes, 1997. p. 61-162. 
Traços de cientificidade, didaticidade e laicidade ...

SILVA, C. E. A.; SOUZA, S. A. C.; MIRANDA, M. R. Solução biode(sa)gradável: componente de detergentes e cosméticos pode dar origem a substâncias tóxicas. Ciência Hoje, São Paulo, v. 43, n. 254, p. 18-23, 2008.

SILVA, H. C.; ALMEIDA, M. J. P. M. O deslocamento de aspectos do funcionamento do discurso pedagógico pela leitura de textos de divulgação científica em aulas de física.

Revista Electrónica de Enseñanza de las Ciencias, Vigo, v. 4, n. 3, p. 155-179, 2005. Disponível em: < http://reec.uvigo.es/volumenes/volumen4/ART8_Vol4_N3.pdf>. Acesso em: 30 out. 2013.

SILVA, P. R. et al. Catalisadores: em busca de estruturas de superfície. Ciência Hoje, São Paulo, v. 36, n. 211, p. 26-29, 2004.

TERRAZZAN, E. A.; GABANA, M. Um estudo sobre o uso de atividade didática com texto de divulgação científica em aulas de física. In: ENCONTRO NACIONAL DE PESQUISA EM EDUCAÇÃO EM CIÊNCIAS, 4., 2003, Bauru. Atas... Bauru: ABRAPEC, 2003. p. 1-11. Disponível em: <http://fep.if.usp.br/ profis/arquivos/ivenpec/ Arquivos/Orais/ORAL172.pdf>. Acesso em: 30 out. 2013.

TOMA, H. E.; ARAKI, K. Nanociência e nanotecnologia: o gigantesco mundo do muito pequeno. Ciência Hoje, São Paulo, v. 37, n. 217, p. 24-31, 2005.

VARELA, M. E. A química do cosmo. Ciência Hoje, São Paulo, v. 40, n. 237, p. 18-23, 2007.

ZAMBONI, L. M. S. Cientistas, jornalistas e a divulgação científica: subjetividade e heterogeneidade no discurso da divulgação científica. Campinas: Autores Associados, 2001.

Artigo recebido em 27/01/13. Aceito em 18/06/13. 